\title{
Contextualising the role of the gatekeeper in social science research
}

\author{
S Singh, ${ }^{1} \mathrm{PhD} ; \mathbf{D}$ R Wassenaar, ${ }^{2} \mathrm{PhD}$ \\ ${ }^{1}$ Department of Dentistry, College of Health Sciences, University of KwaZulu-Natal, Durban, South Africa \\ ${ }^{2}$ South African Research Ethics Training Initiative (SARETI). Discipline of Psychology, School of Applied Human Sciences, University of KwaZulu-Natal, \\ Pietermaritzburg, South Africa
}

Corresponding author: S Singh (singhshen@ukzn.ac.za)

\begin{abstract}
Accessing research participants within some social institutions for research purposes may involve a simple single administrative event. However, accessing some institutions to conduct research on their data, personnel, clients or service users can be quite complex. Research ethics committee chairpersons frequently field questions from researchers wanting to know when and why gatekeeper permission should be sought. This article examines the role and influence of gatekeepers in formal and organisational settings and explores pragmatic methods to improve understanding and facilitation of this process. Conscientious and well-informed negotiations with gatekeepers are required in order to honour the ethical obligations to conduct appropriate stakeholder engagement before and during research, along with respect for the autonomy of institutions and their employees/clients/service recipients. Provision must be made to identify explicit and implicit gatekeepers to initiate and build collaborative networks that could best support the research process. Careful mutually respectful access agreements which consider the needs and vulnerabilities of both the gatekeeper and the researcher can improve the quality of the scientific data collected. Strategic planning in the research process must take these sometimes complex processes of gatekeeper permission into careful account.
\end{abstract}

S Afr J BL 2016;9(1):42-46. DOI:7196/SAJBL.465

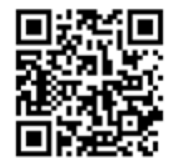

Ethics review of all research, including social and behavioural research, has been mandatory in South Africa (SA) since the introduction of the current National Health Act. ${ }^{[1]}$ In the course of ethics review, research ethics committees (RECs) need to establish that the proposal adheres to applicable ethics guidance..$^{[2]}$ One dimension of such guidance requires that RECs are satisfied that adequate prior community consultation has taken place with research stakeholders. Furthermore, RECs are required to ensure that respect for the autonomy of individuals is assured, usually operationalised through the informed consent process and documents. ${ }^{[3]}$ If the research is to be conducted in an institutional setting and not in the public domain, permission needs to be obtained from the legitimate authorities in charge of such institutions to conduct research in such settings - based on the principle of respect for autonomy. Data suggest that RECs often withhold final ethics approval until the principal investigator (PI) obtains written permission from the authorised signatories of the institution that hosts the intended research participants. ${ }^{[4]}$ This permission is often referred to as gatekeepers' permission which is the focus of this paper.

The role and influence of gatekeepers in social science research has been the subject of some debate and remains a challenge for many researchers. ${ }^{[5,6]}$ Despite most research ethics guidance emphasising the necessity of prior community engagement, including identification and engagement with gatekeepers, published ${ }^{[7]}$ and anecdotal evidence from our own experience as REC chairpersons suggests that many social science researchers view this process as tedious, time-consuming and obstructionist. Reluctance to engage in this process is probably multi-determined and could include the need to meet tight timelines and funding obligations. There are legitimate grounds for debate when research is not being conducted on the physical premises of a specified organisation, for example, employees of organisation $\mathrm{X}$ might be recruited outside the legal entrance of the premises of an organisation, without any physical or electronic violation of the physical boundaries of that organisation. At the same time, entry into an organisation based on deception, disguise, manipulation or false pretences undermines the moral and ethical responsibilities of the researcher. ${ }^{[8]}$ This would be a breach of 'professional propriety and ethics' ${ }^{[8]}$ Researchers are morally and ethically obliged to engage in an open and transparent manner when seeking access to an institution for research purposes.

A gatekeeper is described as someone who controls access to an institution or an organisation such as a school principal, managing director or administrator. ${ }^{[5,9-11]}$ Research conducted in spaces such as shopping malls would also require gatekeeper permission because such spaces are usually privately owned or managed. Research in legitimate public spaces, e.g. streets, sidewalks, parks, public beaches, public markets, neighborhoods, taxi ranks, bus shelters, etc., are usually exempt from gatekeeper permissions, although in SA research in designated traditional areas would require gatekeeper permission from a designated traditional leader. ${ }^{[12,13]}$

All institutions and organisations have an autonomous right to permit or deny access to their information, space, personnel and clients and/or service users for research purposes, unless such information is already published in the public domain.

This article will focus primarily on the role and influence of gatekeepers in formal and organisational settings and explore pragmatic methods to improve understanding and facilitation of this 
process. An understanding of the communication processes and the identification of key stakeholders at various levels of the organisation with the potential to influence the support base for the study are all critical factors to consider. ${ }^{[9,14,15]}$

REC chairs frequently field questions from researchers wanting to know when and why gatekeeper permission should be sought. SA RECs generally agree that a study can only be provisionally approved until the researcher can produce and lodge formal proof of gatekeeper permission, while other RECs might issue full approval with a stipulation that the researcher obtain written proof of gatekeeper permission before recruitment and data collection. Before an REC can approve a study, RECs are required to evaluate whether the intended research site has the resources to host the proposed study, and to consider the possible effects of the study on the site itself. ${ }^{[2,3,6]}$ These are usually covered in a letter of permission from the site gatekeeper. The process of obtaining gatekeeper permission and support for a study may be a dynamic process and researchers need to be aware of multiple influences on this process.

\section{Access and cooperation}

Access to an organisation to conduct research on its data, personnel, clients or service users can be complex, involving either a formal process of gaining entry into an organisation, followed by an informal process where the researcher becomes known to the relevant gatekeepers. It may involve a negotiated transaction between the researcher and the organisation. ${ }^{[8,9]}$ These different points of entry have implications for the research process. A formal process of access would require an understanding of the organisation's operational hierarchy and rules regarding professional etiquette and strategic planning for recruitment and data collection. The informal process involves the researcher's ability to respect the boundaries of the access granted, adopt an objective and formal stance to the research process even if he or she is known to the gatekeepers and research participants. ${ }^{[9]}$ Ethical dilemmas can occur if the gatekeeper is coercive in influencing participant involvement in the research. Conversely, denial of access, by virtue of the researcher's relationship with the gatekeepers, is also a critical issue to consider when planning a project.

Although the terms access and cooperation are used interchangeably, these are different processes. ${ }^{[10]}$ Obtaining gatekeeper permission from the higher levels of the organisation does not, and probably should not, guarantee cooperation from multiple layers of organisational membership, and should never overrule individual autonomy to refuse research participation. ${ }^{[10]}$ It is important that researchers respect and understand the attitudes and contextspecific influences of intermediate gatekeepers within the institution. Both levels of gatekeepers are influenced, driven and shaped by different priorities, which in turn could impact on the project.

\section{Factors to consider}

In order to maximise the possibility of being granted access to an institution for research purposes, it is important that the researcher persuade the gatekeeper (and the REC) of the social value of the study. This is a standard ethics review requirement in biomedical and social science research. ${ }^{[3,16]}$ In addition, the gatekeeper has a right to know the proposed research processes and their potential consequent impact on the normal operational functioning of the institution or organisation, for example, a school principal will want to know how research on learners will impact on class learning time, and possibly even how results might reflect badly on the reputation of her school. The researcher must also articulate the potential risks and/or costs and benefits of the study, with particular reference to the value that this study can bring to the organisation, and similar organisations in question. A clear recruitment process that outlines the nature, process and considerations for participant recruitment is likely to attract a positive decision from the gatekeeper. In some cases, a direct benefit may not be possible and the researcher needs to be explicit about this issue. ${ }^{[10,17]}$ At the very least, the researcher should offer the organisation feedback on the results of the study, as a way of operationalising the ethical obligation of respect for study participants. ${ }^{[3]}$

The recruitment process of potential research participants has an ethical dimension that RECs, gatekeepers and researchers themselves must consider carefully, especially when the researcher is part of the organisation or staffing structure being researched. It might be more difficult for colleagues, clients or service recipients to decline research participation when being recruited by a colleague. This could compromise the voluntariness of research participation and thus undermine the voluntary informed consent requirement. ${ }^{[18]}$ Another example of this could be a scenario where the researcher is an educator/teacher and the study is a classroom-based activity involving learners. Although learners (as research participants) would have been assured of their right to decline or withdraw at any stage of the study, this can be difficult in practice, especially considering the power relations between the educator and the learner and when the research is conducted in classroom activity time. ${ }^{[19,20]}$ Therefore a clear distinction needs to be drawn between the goals of research versus the goals of service delivery to ensure that the host institution's functioning and core services are not disrupted by the research.

All researchers have an ethical obligation to minimise foreseeable risks. These risks could include physical, emotional or informational risks, including pain, discomfort, embarrassment, emotional distress, breach of confidentiality, stigmatisation and ostracism. For example, a researcher investigating sexual violence among school children would need to assure both the gatekeeper (and the REC) that a strategy is in place to ensure confidentiality, privacy and anonymity in addition to outlining the selection and recruitment strategy, as well as providing information about pre-negotiated referral and care facilities for those expressing a need for psychosocial or other relevant support. These strategies must be planned for and clearly articulated in the formal application process for gatekeeper permission. Where the researcher is known to the potential participants, a clear indication should be given on how the researcher will minimise potential bias in sample selection and recruitment and maximise participant voluntariness. Use of non-institutional recruiters might be a sound ethical strategy to overcome these threats to the ethical and scientific quality of the proposed study. Qualitative studies, while utilising seemingly innocuous 'conversations ${ }^{\prime 21,22]}$ can mobilise much stronger emotional distress in participants than impersonal questionnaires or even transient pain caused by minimal risk routine biomedical procedures, and these must be anticipated and planned for. ${ }^{[3]}$ Similarly, focus groups hold threats of disclosure of sensitive information that can harm individuals (and cause organisational instability) which the investigator cannot control, despite appeals to all members 
to observe confidentiality. ${ }^{[18]}$ Researchers should anticipate such issues and assure gatekeepers and RECs that all reasonable precautions to prevent or minimise harm will be taken and monitored.

Broadhead and Rist also outline the potential influence of gatekeepers in determining the conditions of entry into the organisation, access to data and respondents, restricting and wanting control over the scope of data analysis and publication. ${ }^{[8]}$ There may be circumstances where the nature of the research investigation may bring the research into conflict with the organisation, with the real possibility of access being denied. Here again, the researcher needs to engage with the gatekeeper to outline the potential benefits of having to investigate these negative events and to commit to constructive recommendations that will help to improve the organisation. Therefore, there is a need for social skills and professional integrity in such negotiations with gatekeepers.

Other dilemmas could also potentially threaten the integrity of the research process. This is reflected in the scenario where a host institution may wish to influence or manipulate the data, or request access to the raw data. This could be particularly challenging if the researcher is employed in the same company or institution. Another scenario could be when a gatekeeper grants permission for a study and later withdraws support. This could create challenges for the researcher in terms of what happens to the data already collected. In a similar situation, a gatekeeper who granted permission to a student, who was an employee at the institution, resigned. This situation was resolved by allowing all data collected during the period when the gatekeeper permission was valid, to be used for research purposes. All data collected at and after the date of withdrawal was not considered usable. Ideally, the departed gatekeeper's successor should honour the prior permission, but may not always do so. This highlights the importance of anticipating such issues and specifying them in the draft gatekeeper's letter of agreement. Researchers (and RECs) are advised to provide a draft pro-forma of such a letter which specifies the purpose, nature and duration of the study, the sample and recruitment strategy, confidentiality and curation of the raw data, roles of sub-gatekeepers in the organisation (e.g. unit managers), publication, anonymity of the participants and possibly of the host organisation itself. ${ }^{[23]}$ Such a letter could also include agreement on how premature withdrawal by either party will be managed and the fate of the incomplete data set. If unresolved the researcher should seek the advice of the REC that approved the study. RECs should also increase their competence to review such gatekeeper letters, much as Materials Transfer Agreements have become routine for oversight of biological samples over the past few years. ${ }^{[2,25]}$

Researchers should carefully consider any conditions placed by gatekeepers when providing access to staff or information. These conditions, e.g., access to the raw data or restriction on the publication of results, must be carefully considered before being agreed to by the researcher.
Further dilemmas could occur when researchers generate sensitive data that could cast a negative image of the institution. There is a risk of publishing negative results and facing possible alienation or denial of access into the institution for future research. In general, researchers should assure anonymity of the host institution wherever possible, ${ }^{[23]}$ especially if the findings are in the general public good. There may be circumstances where anonymity does not prevent deductive disclosure ${ }^{[26]}$ because the host institution may be one-of-a-kind in the region. ${ }^{[27]}$

\section{A practical guide}

Buchanan et $a^{[28]}$ postulate a four-stage access model involving 'getting in, getting on, getting out and getting back' com-

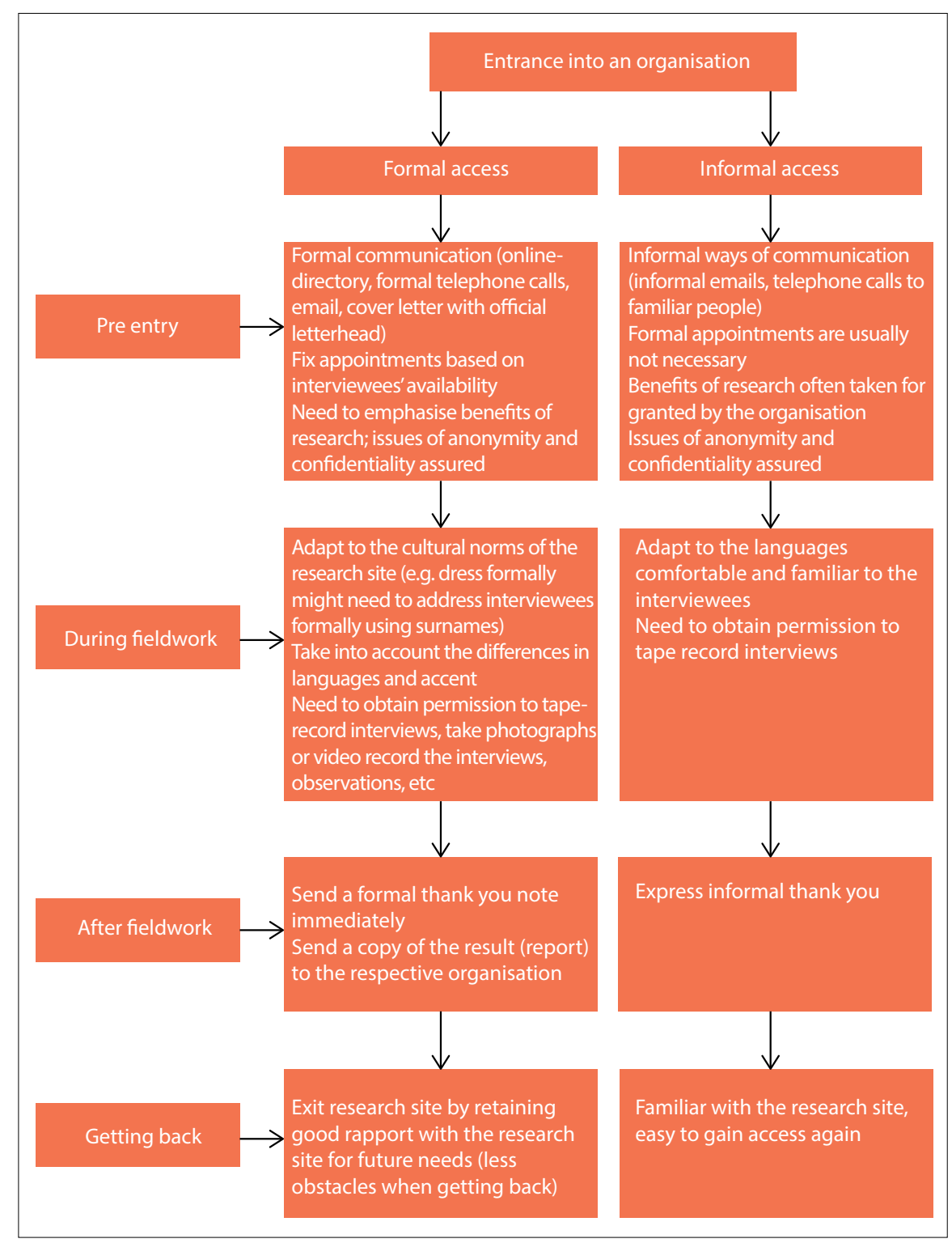

Fig. 1. Process of gaining entrance into an organisation ${ }^{[9]}$ 
ponents. This pragmatic guide could assist researchers in planning for the research process. The 'getting on' component of the model involves communication, personal appearance, tact, respect for persons, and recognition of diversity in culture and social norms and practices. ${ }^{[9,28]}$ The 'getting out' component deals with adherence to agreed timelines to ensure minimal disruption to the host organisation or institutions' operational functioning. The 'getting back' component is perhaps the most critical aspect of the research process. There is increasing concern that researchers are not giving organisations an opportunity to consider and utilise the findings, especially when the findings are negative and could harm the reputation of the host institution or organisation. The ethical obligation of respect requires that researchers provide participants and host institutions with appropriately tailored feedback, to maximise the benefits of the study ${ }^{[3]}$ which, for example, allows the organisation to plan remedial measures if indicated by the data.

Johl and Renganathan also provide a useful phased framework for responsible engagement with organisations and their gatekeepers. They refer to the various components as 'pre-entry', 'during fieldwork', 'after fieldwork' and 'getting back..9] The pre-entry phase identifies both the formal and informal process of initiating communication with the gatekeepers (Figure 1). This process should be seen as a layered approach, fostering communications at multiple levels of gatekeeping. Issues such as recruitment of participants, impact on the organisation's operational functions, confidentiality and anonymity must be explicitly outlined. There is therefore a need for strategic planning to build gatekeeper trust and support for the project. The researcher should also ensure that ethics review and approval from a registered REC are in place before data collection commences.

In the fieldwork phase, the researcher must ensure that all activities captured in the gatekeeper agreement letter are adhered to. Informed consent must be obtained from the individual participants for all aspects of the data collection process. Participants should be given the right to accept or reject the use of audio or video recorders or the use of photographs. In addition, the researcher should respect cultural diversity and the social dynamics that prevail in that work environment. The researcher should also adhere to the agreed timelines for data collection and ensure minimal disruption of the operational functioning of the institution. It is also good practice to send a note of appreciation to the gatekeeper at the end of the study.

Feedback sessions, where agreed to, should be done in a constructive manner, even when the study results are negative. There is an ethical obligation to present feedback in a form that is tailored to the audience so as to maximise understanding, utility and implementation, with acknowledgement of the limitations of the data, as required by scientific integrity guidance. ${ }^{[29,30]}$ Feedback sessions could be conducted in different ways, for example, a presentation, workshop, event, or a summary electronic or hard copy report, tailored for each specific audience.

\section{Conclusion}

Gatekeepers play an essential and undervalued role in the generation of good research data. Conscientious and well-informed negotiations with gatekeepers are required in order to honour the ethical obligations to conduct appropriate stakeholder engagement before and during research, along with respect for the autonomy of institutions and their employees/clients/service recipients. Careful mutually respectful access agreements, which consider the needs and vulnerabilities of both the gatekeeper and the researcher, can improve the quality of the scientific data collected. Strategic planning in the research process must take these sometimes complex processes of gatekeeper permission into careful account. Although gatekeeping permissions are often a simple single administrative event, this is not always the case. It can be a complex, layered process approach involving layers of gatekeepers with the potential to influence the data collection process. Researchers should be respectful of this and well prepared to consider and understand gatekeepers' concerns. Provision must be made to identify explicit and implicit gatekeepers to initiate and build collaborative networks that could best support the research process, bearing in mind that these collaborations could be biased by vested interests. Respectful work with gatekeepers will ensure that good quality social science research is conducted with consideration and respect for all parties concerned.

We hope that this article stimulates more critical reflection and practice by RECs and researchers of the role of gatekeepers in research. Future research could examine gatekeepers' own perspectives on the issues arising when hosting researchers in institutional research settings.

\section{References}

1. Cleaton-Jones $P$, Wassenaar, D. Protection of human participants in health research: A comparison of some US Federal Regulations and South African Research Ethics guidelines. S Afr Med J 2010;100(11):710-716.

2. Department of Health, South Africa. Ethics in research: principles, processes, structures. Pretoria: National Health Research Ethics Council, 2015: 9-17.

3. Wassenaar DR, Mamotte N. Ethical issues and ethics reviews in social science research. In: Leach M, Stevens M, Lindsay G, Ferrero A, Korkut Y, eds. The Oxford Handbook of International Psychological Ethics. New York: Oxford, 2012:268-282.

4. Denny SG, Silaigwana B, Wassenaar D, Bull S, Parker M. Developing ethical practices for public health research data sharing in South Africa: The views and experiences from a diverse sample of research stakeholders. J Empir Res Hum Res Ethics 2015:10(3):290-301. DOI:10.1177/1556264615592386

5. Clark T. Gaining and maintaining access: Exploring the mechanisms that support and challenge the relationship between gatekeepers and researchers. Qual Soc Work 2011;10(4):485-502. DOI:10.1177/1473325009358228

6. Das C, McAreavey R. A delicate balancing act: Negotiating with gatekeepers for ethical research when researching minority communities. Int J Qualit Methods 2013;12(1):113-131. DOI:10.1177/160940691301200102

7. Seahloli MS. Challenges encountered when applying for ethics and permission to conduct the non-clinical trial study in the hospitals and clinic. S Am J Clinic Res 2015:2(1):1-14.

8. Broadhead RS, Rist RC. Gatekeepers and the social control of social research. Soc Probs 1976;23(3):325-336. DOI:10.1525/sp.1976.23.3.03a00080

9. Johl SK, Renganathan S. Strategies for gaining access in doing fieldwork: Reflection of two researchers. EJBRM 2010;8(1):42-50.

10. Wanat CL. Getting past the gatekeepers: Differences between access and cooperation in public school research. Field Meth 2008:20(2):191-208. DOI 10.1177/1525822X07313811

11. Wiles $R$, Heath $S$, Crow $G$, Charles V. Informed consent in social research: A literature review. Southhampton: ESRC National Centre for Research Methods. NCRM Methods Review Papers. NCRM/001. University of Southampton, 2005. http://eprints.ncrm.ac.uk/85/1/MethodsReviewPaperNCRM-001.pdf (accessed 10 January 2016)

12. Mandel J. Negotiating expectations in the field: Gatekeepers, research fatigue and cultural biases. Singapore J Trop Geog 2003;24(2):198-210. DOI:10.1111/14679493.00152

13. Matshidze PE. The role of Makhadzi in traditional leadership among the Venda. A thesis submitted in fulfilment of the degree of Doctor in Philosophy. KwaZuluNatal: University of Zululand, 2013. http://uzspace.uzulu.ac.za/bitstream/ handle/10530/1327/THE+ROLE+OF+MAKHADZI+IN+TRADITIONAL+LEADERSHI P+AMONG+THE+VENDA.pdf (accessed 20 March 2016).

14. Herd B. The wizard and the gatekeeper: Of castles and contracts. BMJ 1995;310(6986):1042-1044.

15. Willems DL. Balancing rationalities: Gatekeeping in health care. J Med Ethics 2001;27(1):25-29. 
16. Emanuel EJ, Wendler $D$, Grady C. An ethical framework for biomedical research. In: Emanuel EJ, Grady C, Crouch RA, Lie RK, Miller FG, Wendler D, eds. The Oxford textbook of clinical research ethics. New York: Oxford University Press, 2008:123-133.

17. Campbell J. Ethical Considerations with Gatekeepers. Mark Bound Nova Southeastern DCAR 7120NSU PhD. Program. 10, April 2012. https://www. academia.edu/1526314/Ethics_in_Qualitative_Research_Gatekeepers (accessed 20 March 2016)

18. Mamotte N, Wassenaar DR. Voluntariness of consent to HIV clinical research: A conceptual and empirical pilot study. J Health Psychology 2016; 1-18. DOI: $10.1177 / 1359105316628737$

19. Heath S, Charles V, Crow G, Wiles R. Informed consent, gatekeepers and gobetweens. Amsterdam: International Association Sixth International Conference on Social Science Methodology, 2004. http://www. sociologyandsocialpolicy.soton.ac.uk/Proj/Informed_Consent/Resources.html (accessed 10 December 2015).

20. Homan R. The principle of assumed consent: The ethics of gatekeeping. J Philos Educ 2001;35(3):329-43. DOI:10.1111/1467-9752.00230

21. Redwood S, Todres L. Exploring the ethical imagination: Conversation as practice versus committee as gatekeeper. Forum: Qualitat Soc Res 2006:7(2):26.

22. Schrag ZM. How talking became human subjects research: The federal regulation of the social sciences 1965-1991. J Policy History 2009:21(1):3-37. DOl:10.1017/ s0898030609090010
23. Uys LR. Should researchers protect the good name and reputation of institutions in which research is done? S Afr J Higher Educ 2008:22(2):457-465.

24. Barchi F, Matshlagela K, Jones N, Kebaabetswe PM, Merz JM. The keeping is the problem: A qualitative study of IRB-member perspectives in Botswana on the collection, use and storage of human biological samples for research. BMC Med Eth 2015;16(3):54. DOI:10.1186/s12910-015-0047-3

25. Staunton C, Moodley K. Data mining and biological sample exportation from South Africa: A new wave of bioexploitation under the guise of clinical care? S Afr Med J 2016;106(2):136-138. DOI:10.7196/SAMJ.2016.v106i2.10248

26. ACH Media. Avoid'deductive' disclosures by revamping informed consent. Atlanta: ACH Media, 2010. http://www.ahcmedia.com/articles/115236-avoid-deductivedisclosures-by-revamping-informed-consent (accessed 10 January 2016).

27. Kaiser K. Protecting respondent confidentiality in qualitative research. Qual Health Res 2009;19(11):1632-1641. DOI:10.1177/1049732309350879

28. Buchanan D, Boddy D, Mc Calman J. Getting In, Getting On, Getting Out and Getting Back. In: Bryman A, ed. Doing Research in Organisations. London: Routledge, 1988: 53-67.

29. Fernandez CV, Kodish E, Weijer C. Informing study participants of research results: An ethical imperative. IRB 2003;25(3):12-19. DOI:10.2307/3564300

30. Thorogood A, Joly Y, Knoppers BM, et al. An implementation framework for the feedback of individual research results and incidental findings in research. BMC Med Ethics 2014;15(1):88. DOI:10.1186/1472-6939-15-88 